\title{
NESTING BIOLOGY OF URBAN COOPER'S HAWKS IN ALAMEDA COUNTY, CALIFORNIA
}

\author{
RALPH V. PERICOLI, Golden Gate Raptor Observatory, Golden Gate National \\ Parks Conservancy, Building 1064, Fort Cronkhite, Sausalito, California 94965 \\ EMMA L. KARSTEN, Hamilton College, Environmental Studies Program, 198 \\ College Hill Rd, Clinton, New York 13323
}

ALLEN M. FISH, Golden Gate Raptor Observatory, Golden Gate National Parks Conservancy, Building 1064, Fort Cronkhite, Sausalito, California 94965

CHRISTOPHER W. BRIGGS, Colgate University, 13 Oak Dr., Hamilton, New York 13346; cbriggs@colgate.edu

ABSTRACT: In recent decades Cooper's Hawks have successfully colonized urban landscapes, where there may be ample prey but also a greater prevalence of disease in their prey. We searched for nesting Cooper's Hawks in and around Berkeley, California, from 2002 to 2010 , locating 95 nests, 89 of which successfully fledged at least one nestling. On average, each nest produced 3.6 fledglings. We evaluated the possible effects of the protozoan parasite Trichomonas gallinae on Cooper's Hawk reproduction from the proportion of potential prey items brought to Lindsay Wildlife Experience that tested positive for the parasitic disease. We did not find a correlation between T. gallinae in potential prey species and nest success (i.e., if the nest fledged any offspring) or reproductive success (i.e., number of fledglings produced). Similarly, we did not find a relationship between reproductive success and distance to parks or percent of impervious surface within $500 \mathrm{~m}$ of the nest. The high reported rates of reproduction and high densities of Cooper's Hawk in Berkeley and neighboring Albany suggest a robust population, and we did not find evidence that T. gallinae influences its reproductive success.

The Cooper's Hawk (Accipiter cooperii) is a common woodland hawk that often focuses on birds as prey (Rosenfield et al. 2019b). While it nests throughout the United States and boreal Canada in a variety of tree species in dense woods (Rosenfield et al. 2019b), in recent decades it has adapted to urban habitats (Boal and Mannan 1998). Cooper's Hawks in more urban environments differ in behavior and nesting habitats (Mannan and Boal 2000, Estes and Mannan 2003, Stout et al. 2007, Chiang et al. 2012, Millsap 2018). In southern California, for example, rural Cooper's Hawks typically use oak and riparian woodland, whereas their urban counterparts use parks and ornamental plantings (Chiang et al. 2012). Urban pairs are also more tolerant of human approaches to the nest and are bolder than their nonurban counterparts (Boal and Mannan 1999).

Urban habitats may not be productive or self-sustaining for Cooper's Hawks, acting as population sinks, which rely on immigration to maintain stable populations (Reynolds 1983, Bosakowski et al. 1993). However, some urban environments may actually confer advantages on the hawk populations, such as increased prey populations (Millsap 2018). In contrast, Mannan et al. (2008) and Boal et al. (1998) found negative effects of urbanization in Tucson, Arizona, which may function as a population sink for Cooper's Hawks, where populations need to be replenished by immigration from outside populations. Specifically, in doves, the primary prey of urban Cooper's Hawks in Tucson, they found a high prevalence of disease caused by 
the protozoan parasite Trichomonas gallinae. As a result, there was a much higher rate of T. gallinae infection in urban than in exurban hawk nestlings (85\% versus 9\%, respectively; Boal et al. 1998). Boal et al. (1998) hypothesized that a greater availability and abundance of prey in Tucson draws Cooper's Hawks to the city, where adults may deliver twice as much prey to nests as do rural Cooper's Hawks (Estes and Mannan 2003). However, the presence of T. gallinae in the abundant urban prey impairs the hawks' productivity (Boal et al. 1998).

Still, studies of Cooper's Hawks in other urban areas indicate that some populations may be well adapted to increased urbanization (Stout and Rosenfield 2010, Chiang et al. 2012, Millsap 2018). For example, in Orange County, California, urban-nesting Cooper's Hawk pairs produce significantly more young on average than do non-urban pairs (Chiang et al. 2012). Similarly, Stout et al. (2007) found that urban Milwaukee, Wisconsin, was not an ecological sink for Cooper's Hawk, citing long-term high reproduction rates, repeated re-occupancy of nest sites, and confirmed recruitment from within the population. In central New Mexico urban Cooper's Hawks also represent a source population instead of a sink, and urban hawks outcompete exurban hawks through their ability to overwinter in the city instead of migrating (Millsap 2018).

Given differences between populations in reproductive rates in urban areas, we examined the nesting biology of an urban Cooper's Hawk population in the city limits of Berkeley and Albany in Alameda County, California. We excluded San Francisco baylands west of Interstate 80 and largely inaccessible University of California lands uphill from the university's campus. The resulting study area was roughly rectangular, measuring 5.9 by $4.7 \mathrm{~km}$ and covering approximately 2780 ha.

During a long-term study of nesting Cooper's Hawks, we assessed apparent nest success (i.e., nest success not corrected for biases in missing nests that failed earlier in the season; Mayfield 1961), nest productivity, nest location, nest density, and habitat preferences. Additionally, we examined long-term data on the prevalence of T. gallinae in potential prey species brought to a local wildlife-rehabilitation center to determine if the hawk's annual productivity in Berkeley was related to the rates of the parasite's incidence in potential prey, as it was in Tucson (Boal et al. 1998). We hypothesized that the prevalence of T. gallinae should depress the average yearly productivity of Cooper's Hawk nests in Berkeley. We also predicted that nesting territories with less vegetation and more impervious surfaces should be less productive because of their greater abundance of prey possibly infected with T. gallinae.

\section{METHODS}

In February 2002, we recruited volunteers from the Golden Gate Raptor Observatory, each with a minimum of three years of experience in counting or banding accipiters, to locate and monitor Cooper's Hawk nests in Berkeley and Albany. In subsequent years, we added experienced birders as needed to cover the study area. Intensive nest searches and monitoring continued annually through the breeding season of 2010. Each volunteer was trained in how to identify and monitor Cooper's Hawk nest structures and plucking perches 
(i.e., locations where hawks regularly remove feathers and other inedible parts of prey). We located potential nest structures prior to deciduous trees leafing out and monitored those structures through the breeding season (Figure 1). In addition, we monitored for signs of nesting activity (e.g., calling adults, flight displays, etc.) and surveyed for alternate nests (i.e., other potential nests within a nesting territory; Steenhof et al. 2017).
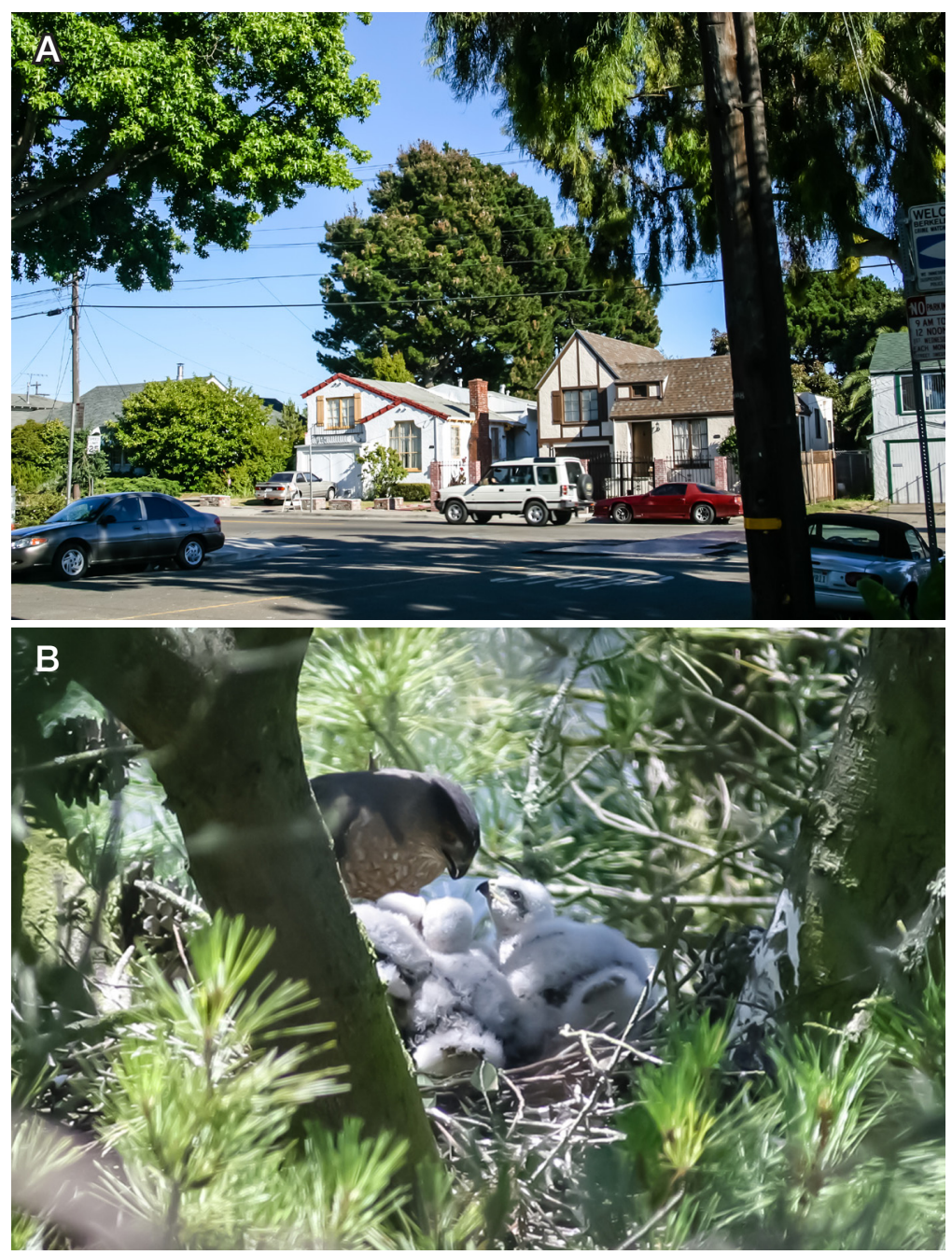

Figure 1. (A) Typical Cooper's Hawk nest tree, a Monterey Pine, Pinus radiata, along a Berkeley street. (B) Adult female Cooper's Hawk attending five 2-week-old nestlings. 
Once a nest was located we mapped its location and monitored it approximately once every two weeks, visually confirming activity at the nest, counting offspring whenever possible, or noting no activity after approximately one hour. We used binoculars and spotting scopes to count the number of offspring from a safe distance, and assumed a nest had failed when there was no activity at it on two consecutive visits each representing observation for approximately one hour. All counts of nestlings were confirmed by a second experienced observer. Nests were considered successful if any nestling was able to start branching (i.e., leaving the nest and perching on adjacent limbs).

We classified nests as being found within a park, on the University of California campus, along a city street, or in a residential back yard. We identified the species of tree supporting each nest, and calculated the distance to the next nearest active nest each year. We used ArcGIS to measure the percent of impervious surfaces such as cement and asphalt (available from https://www. cityofberkeley.info/gisportal/). We estimated the percent cover of vegetation in each pair's home range, defined as circle of radius $0.5 \mathrm{~km}$ around its nest, visually by using aerial imagery from Google Earth.

We estimated the prevalence of $T$. gallinae in potential prey species (i.e., Passeriformes and Columbidae) from its incidence in 3439 wild birds brought to the Lindsay Wildlife Experience in Walnut Creek, California, from 2002 to 2010. Typically, these birds came from Alameda and Contra Costa counties, but some were from farther away. Using a logistic regression $(P>0.05$ for all comparisons), we did not find a difference in proportion of individuals affected across counties, so we combined all data. We recorded physical symptoms, such as large caseous lesions on the mouth and throat, when they were consistent with T. gallinae. In addition to measuring the overall proportion of birds infected each year, we calculated the percent of infected birds of each species for each year as an index of disease risk for each year of the study. We selected four species documented as Cooper's Hawk prey in previous studies that were also common in the sample of birds received at Lindsay Wildlife Experience-the Mourning Dove (Zenaida macroura), House Finch (Haemorhous mexicanus), and Lesser (Spinus psaltria) and American (S. tristis) goldfinches-and from the prevalence of T. gallinae in these species calculated a single variable by pooling all samples. While we examined individual birds showing visible signs of T. gallinae, we also tested a subset of individuals by examining swabbed cloanal cells under a microscope. Annual measures of the proportion of individuals showing macroscopic symptoms of T. gallinae and those positive when swabbed were highly correlated (Pearson correlation coefficient $=0.84, t_{7}=4.0, P=0.005$ ).

We examined nest success and productivity with generalized linear mixed models, using the package lme4 (Bates et al. 2015) in R 3.5.3 (R Core Team 2017). Territory and year represented repeated measures within the logistic and quasi-Poisson families, respectively. For each response variable we examined tree species, year, percent impervious cover, and percent vegetation within a territory. We used backwards stepwise selection to find the most parsimonious model, and assumed $\alpha=0.05$ for all analyses.

We used a simple linear regression to examine the relationship between average annual productivity across the study area and prevalence of T. gallinae. We also used a simple linear regression to examine the relationship 
between apparent annual nest success across the study area and prevalence of the parasite.

\section{RESULTS}

From 2002 through 2010 we located 95 Cooper's Hawks nests in Berkeley and Albany, averaging 10.6 nests located each year of the study (Figure 2). Of these nests, $89(94 \%)$ were successful in producing at least one fledgling (Table 1). Apparent nest success was 100\% for all years except 2003 (75\%) and $2009(63 \%)$. Mean productivity $( \pm$ SD) across the study was $3.4 \pm 1.2$ fledglings/nest, and productivity of successful nests was $3.6 \pm 0.8$ fledglings/ nest. The largest number of nests $(n=36 ; 37 \%)$ was found in trees along (i.e., within $3 \mathrm{~m}$ of) streets and sidewalks, with the remainder being found in local parks $(n=25)$, on the University of California campus $(n=22)$, or in the back yards of homes $(n=13)$. The nesting period was primarily February through the end of June (Table 2). Nests were most commonly found in ash trees (Fraxinus spp.; $n=21$ ), but also in eucalyptus (Eucalyptus spp.; $n=14$ ), American elm (Ulmus americana; $n=13$ ), and Monterey pine (Pinus radiata; $n=13$ ), among other less important species.

On average, nests had a large proportion of impervious surface $(89.8 \%$ $\pm 10.9 \%$ ) within a radius of $0.5 \mathrm{~km}$. In addition, nests tended to be closely spaced; the average distance to the nearest neighbor was $999.7 \mathrm{~m} \pm 380.5 \mathrm{~m}$. There was no relationship between category of nest location (i.e., park, campus, backyard, or street), percent impervious surface in a territory, amount

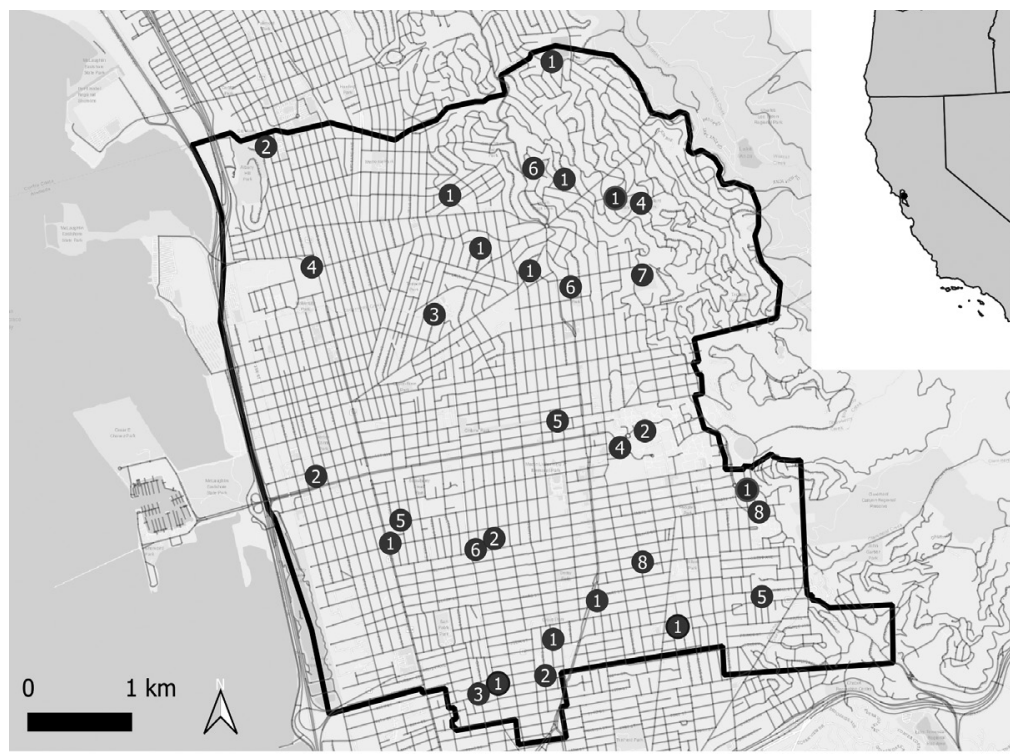

FiguRe 2. Nest sites of Cooper's Hawk in the city of Berkeley from 2002 through 2010. Numbers indicate the number of years a nest was found within a radius of $50 \mathrm{~m}$. 
TABle 1 Annual Counts, Productivity, and Density of Cooper's Hawk Nests in Berkeley, California, and Prevalence of Trichomonas gallinae in Possible Prey Admitted to Lindsay Wildlife Experience

\begin{tabular}{lcccccc}
\hline & $\begin{array}{c}\text { Total } \\
\text { nests }\end{array}$ & $\begin{array}{c}\text { Successful }_{\text {nests }^{a}} \\
\text { productivity }^{b}\end{array}$ & $\begin{array}{c}\text { Tverage } \\
\text { productivity/ } \\
\text { nest }\end{array}$ & $\begin{array}{c}\text { Density } \\
\text { (ha/pair) }\end{array}$ & $\begin{array}{c}\text { T. gallinae } \\
\text { prevalence } \\
\left(\% \text { of } n^{c}\right)\end{array}$ \\
\hline 2002 & 12 & 12 & 40 & 3.3 & 232 & $1.4(521)$ \\
2003 & 12 & 9 & 36 & 3.0 & 309 & $1.7(527)$ \\
2004 & 14 & 14 & 53 & 3.8 & 199 & $1.7(236)$ \\
2005 & 10 & 10 & 41 & 4.1 & 278 & $4.3(369)$ \\
2006 & 12 & 12 & 39 & 3.3 & 232 & $4.2(391)$ \\
2007 & 11 & 11 & 41 & 3.7 & 253 & $2.0(333)$ \\
2008 & 9 & 9 & 32 & 3.7 & 309 & $3.0(344)$ \\
2009 & 8 & 5 & 16 & 3.2 & 397 & $3.6(376)$ \\
2010 & 7 & 7 & 25 & 3.6 & 397 & $3.5(331)$ \\
Average & 10.6 & 9.9 & 36.2 & 3.5 & 289.6 & $2.8(281)$ \\
\hline
\end{tabular}

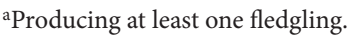

${ }^{b}$ Number of nestlings fledged.

Number of individuals of prospective prey tested.

of vegetation within a territory, or distance to nearest neighbor with either nest success or productivity $(P>0.07$ for all relationships).

The prevalence of T. gallinae in birds brought to Lindsay Wildlife Experience ranged from 1.4 to $4.3 \%$ over the course of the study (Table 1). There was no relationship between this prevalence in any prey species and annual apparent success of Cooper's Hawk nests $(P>0.42$ for all relationships, $n=$ 9). Similarly, there was no relationship between prevalence of T. gallinae and average annual productivity across the study site $(P>0.30$ for all relationships, $n=9$; Figure 3 ).

TABLE 2 Phenology of Cooper's Hawks Nesting in Berkeley, California

\begin{tabular}{lccccc}
\hline & Pair on territory & & & & \\
& Nest building & & Observed & & \\
incubation & Hatching date & Branch date $^{c}$ \\
\hline 2002 & 13 Feb-20 Apr & 27 Feb-22 Mar & 30 Mar-19 Apr & 6-23 May & 4-28 Jun \\
2003 & 30 Jan-7 Mar & 21 Feb-8 Apr & 7-27 Apr & 8 May-10 Jun & 15 Jun-9 Jul \\
2004 & 11 Jan-27 Feb & 28 Feb-14 Mar & 2-17 Apr & 5-28 May & 10-28 Jun \\
2005 & 1-16 Mar & 7-10 Mar & 10-18 Apr & 20 May-8 Jun & 11-30 Jun \\
2006 & 7-24 Mar & 25 Feb-14 Apr & 10 Apr-12 May & 17 May-13 Jun & 14-27 Jun \\
2007 & 1 Feb-23 Mar & 4 Feb-28 Apr & 14-28 Apr & 7-26 May & 15 Jun-2 Jul \\
2008 & 10 Feb-23 Mar & 7 Mar-6 Apr & 6-19 Apr & 11-27 May & 17-28 Jun \\
2009 & 2 Feb-6 Mar & 19 Feb-7 Mar & 13-19 Apr & 26 May-7 Jun & 17-26 Jun \\
2010 & 6 Feb-23 Mar & 6 Feb-24 Mar & 5-26 Apr & 15 May-4 Jun & 19 Jun-2 Jul \\
Range & 11 Jan-20 Apr & 4 Feb-28 Apr & 30 Mar-12 May & 5 May-13 June & 4 Jun-9 Jul \\
\hline
\end{tabular}

${ }^{a}$ When pairs were observed defending, using alarm calls, or displaying (e.g., fanned-tail display).

${ }^{b}$ Defined by observations of adult hawks carrying materials to a nest structure.

${ }^{c}$ Date on which young began moving among the branches of the nest tree. 


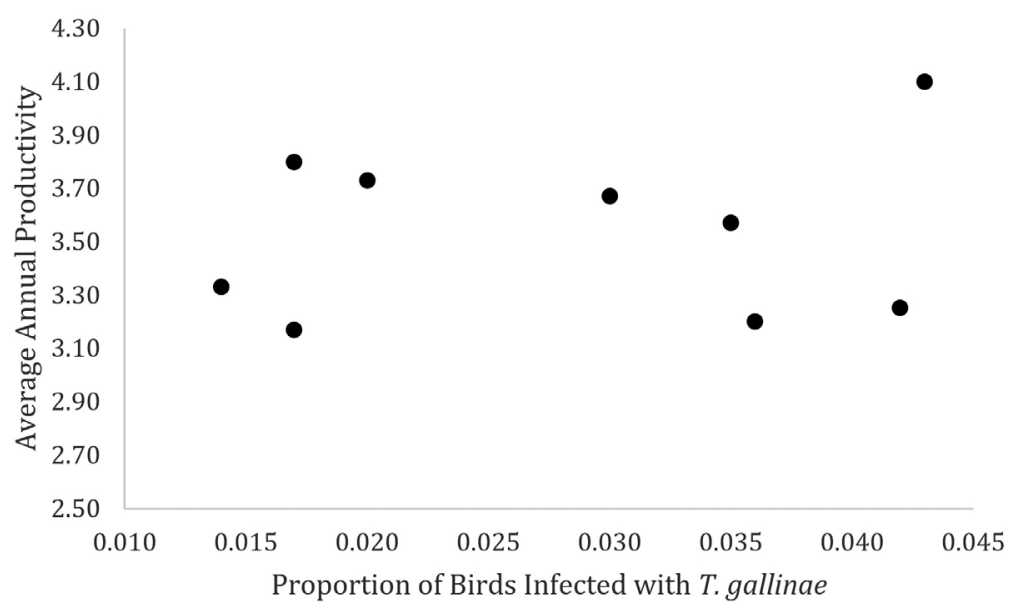

FIGURE 3. Relationship between nest productivity of Cooper's Hawks in Berkeley and prevalence of Trichomonas gallinae in four common potential species of prey brought into Lindsay Wildlife Experience in Walnut Creek, California, from 2002 through 2010. Each point represents the incidence in the Mourning Dove, House Finch, American Goldfinch, and Lesser Goldfinch pooled over one year.

\section{DISCUSSION}

The prevalence of infection with T. gallinae in potential prey did not influence Cooper's Hawks' nest success or productivity in our Alameda County study area. The high rate of productivity and lack of apparent deleterious effect of diseased prey on reproduction indicates that Berkeley has the potential to be a population source (i.e., population from which there is net emigration) for Cooper's Hawk, in contrast to Tucson (Boal et al. 1998; but see Mannan et al. 2008). Nevertheless, T. gallinae has been found in Cooper's Hawks within the study area (Lindsay Wildlife Experience, unpubl. data). While we found no relationship between disease prevalence in prey and hawk reproduction, we did not test hawk nestlings or fledglings for T. gallinae. Rather, our data on the disease's prevalence came only from tests on birds brought to a local wildlife hospital. Many birds admitted were not swabbed for T. gallinae, which could have affected the results for disease prevalence. Additionally, we assumed that the birds brought to Lindsay Wildlife Experience reflected the relative prevalence of the disease in the local region, and should therefore reflect the local exposure of Cooper's Hawks. In addition, with only six monitored nests failing and reproductive success very high throughout the 10 years of the study, the effects of disease could be difficult to detect, and more targeted monitoring to clarify the effects of T. gallinae on this population is appropriate.

The average productivity of 3.6 fledglings per nest per laying pair is high compared to other urban Cooper's Hawk populations, and similar to the averages of 4.1 fledglings in Oshkosh, Wisconsin, and 3.5 fledglings in Stevens Point, Wisconsin (Rosenfield et al. 2019a). Stout et al. (2010) found an aver- 
age of 2.6 nestlings per laying pair of urban Cooper's Hawks in Milwaukee, Wisconsin, while Boal (1997) found an average of 3.1 nestlings per laying pair in Tucson, Arizona. Additionally, the Berkeley population's nest-success rate of $94 \%$ is among the highest reported for urban Cooper's Hawks, exceeding the rates of $84 \%$ around Tucson (Mannan et al. 2008), $47 \%$ in urban Tucson (Boal and Mannan 1999), and 65\% in Milwaukee (Stout et al. 2010). While we measured only apparent nest success and therefore are likely overestimating true nest success across the study (Mayfield 1961), the studies with which we compare our rates similarly used apparent nest success. Future work should focus on estimating the Berkeley population's rate of daily nest survival to determine if our relatively small sample sizes could be influencing detection and causing more bias in our estimate of nest success.

Not only are its rates of nesting success and productivity high, the density of the Berkeley population of Cooper's Hawk is high. An average density of 1 nest per 290 ha over the course of the study (and 1 nest per 199 ha in 2004) is among the highest reported for Cooper's Hawk. Densities of Cooper's Hawk nests range from 1 per 671 to 2326 ha in the western U.S. (Reynolds 1989) and 1 per 331 to 5000 ha in eastern states (Rosenfield et al. 1991). In comparison to the densities of other urban Cooper's Hawk populations studied-1 nest per 101 ha in Albuquerque, New Mexico (Millsap 2018), 1 nest per 437 ha in Tucson (Boal and Mannan 1998), 1 nest per 272 ha in Stevens Point, Wisconsin (Rosenfield et al. 1995), and 1 nest per 238 ha in Oshkosh, Wisconsin (Rosenfield et al. 2019a) - that of the Berkeley population is also one of the highest observed. Despite this high density, our estimate is likely biased low because we could not access many private yards, and detection of nests was likely not $100 \%$.

These high rates of nest success and productivity and high population density indicate that the city of Berkeley is good-quality habitat for Cooper's Hawk. This population supports the hypothesis of Rosenfield et al. (1995) that urban areas allow for denser Cooper's Hawks populations than do rural areas. Urban areas have been shown to have elevated abundances of prey (Chamberlain et al. 2009). The greater density of prey in urban areas (Bird et al. 1996, Boal and Mannan 1998) may be responsible for the high density of Berkeley's Cooper's Hawk population.

Such high densities of prey may mean that nesting Cooper's Hawks do not need natural areas to find adequate prey. We found no relationship between reproduction and the extent of impervious surface within a territory, which is consistent with previous studies' findings that human disturbance and land use does not seem to affect Cooper's Hawk's nest-site selection (Boal and Mannan 1998, Rullman and Marzluff 2014). For example, Rullman and Marzluff (2014) found that Cooper's Hawks seemed to prefer areas of mixed vegetation and urban surfaces over wooded areas, which can also explain the high density of Cooper's Hawks in the urban environment of Berkeley.

As these data have shown, the city of Berkeley constitutes an attractive and successful breeding habitat for Cooper's Hawks. Despite these indications of a healthy population, more work needs to be done to determine if the Berkeley area serves as a population source or sink. For example, other factors, such as low rates of survival of juveniles or adults, could mean that this population is also a sink despite its high productivity. 
Additionally, the diet of Berkeley Cooper's Hawks should be compared to that of other urban Cooper's Hawks, and the role of prey abundance and diversity in the high success rate of the Berkeley population should be considered. By further understanding the features that promote occupancy of Cooper's Hawks, we can better understand the role of urban environments in source/sink dynamics and how disease may play a role in that process.

Additionally, this study demonstrates the ability of volunteers to locate, monitor, and collect data on nesting Cooper's Hawks, guided by supervising biologists. Community scientists successfully located and monitored 96 Cooper's Hawks nests over 9 years in an urban setting and recorded the birds' performance in breeding. These data provide evidence for a robust raptor population in an urban environment, with higher densities and reproductive success than has been previously documented in the literature. The study also demonstrates the ability of community scientists to maintain long-term studies and collect meaningful data.

\section{ACKNOWLEDGMENTS}

This study could not have been conducted without the nest searching and monitoring by the dozens of volunteer community scientists of the Golden Gate Raptor Observatory (GGRO). Great thanks to Anne Ardillo, Laura Baker, Muki Belliappa, Ande Bennett, Christopher Berner, Tony Brake, Tisha Brewster, Jim Brulet, Jerry Connell, Lewis Cooper, Judith Dunham, Rick Elefant, Tom Felts, Julia Goldzmann, Greg Gothard, Dorothy Gregor, Jerry Hadfield, Aaron Haiman, Joshua Haiman, Mike Hall, Diane Jacobs, Eric Jepsen, Barbara Kelly, Sterling Kinnell, Carolyn Kolka, Ann Kositsky, Allison Levin, Charlene Lewis, Ed Lewis, Ina Lockwood, Fran McDermott, Yvonne McHugh, Fraser Meachem, Horacio Mena, Mona Mena, Paul Mirocha, Lisa Morse, Bob Numerof, Lisa Owens Viani, Ron Parker, Bill Prochnow, Jennie Rhine, Matt Ricketts, Anne Rock, Steve Rock, Kari Rodenkirchen, Jim Ross, Juta Savage, David Sexton, Robert Shepard, Karen Smith, Robert Smith, Polly Strahan, Jennifer Sullivan, Jan Sutcher, Cooper Walton, Martha Wilson, Step Wilson, Ken Windler, and Kathy Wolf.

We greatly appreciate the help of Amber Engle, Carlos de la Rosa, and the staff and volunteers of Lindsay Wildlife Experience for their help and cooperation collecting and sharing data on Trichomonas in San Francisco Bay Area bird populations. Leadership and advice for the study came from many individuals, including Buzz Hull, Mark Fenn, Reg Barrett, Aaron Haiman, Tony Brake, Karen Smith, Anton Muniz, Tina Cheng, Carla Cicero, Hans Peeters, Ryan McDougald, Jim DeRoque, and Bill Mannan. The GGRO is a long-term conservation-science program of the Golden Gate National Parks Conservancy in cooperation with the National Park Service. We are deeply appreciative of the generous support of the Gregory Hind Endowment, and of the hundreds of volunteers and donors who support the GGRO. This is GGRO scientific contribution number 155. Thank you to reviewers Robert Rosenfield, Kimball Garrett, and one anonymous reviewer for improvements to the manuscript.

\section{LITERATURE CITED}

Bates, D., Maechler, M., Bolker, B., and Walker, S. 2015. Fitting linear mixed-effects models using lme4. J. Stat. Software 67:1-48; doi.org/10.18637/jss.v067.i01.

Bird, D. M., Varland, D. E., and Negro, J. J. 1996. Raptors in Human Landscapes: Adaptations to Built and Cultivated Environments. Academic Press, London. 
Boal, C. W. 1997. The urban environment as an ecological trap for Cooper's Hawks. Ph. D. dissertation, Univ. Ariz., Tucson.

Boal, C. W. 2001. Nonrandom mating and productivity of adult and subadult Cooper's Hawks. Condor 103:381-385; doi.org/10.1093/condor/103.2.381.

Boal, C. W., and Mannan, R. W. 1998. Nest-site selection by Cooper's Hawks in an urban environment. J. Wildlife Mgmt. 62:864-871; doi.org/10.2307/3802537.

Boal, C. W., and Mannan, R. W. 1999. Comparative breeding ecology of Cooper's Hawks in urban and exurban areas of southeastern Arizona. J. Wildlife Mgmt. 63:77-84; doi.org/10.2307/3802488.

Boal, C. W., Mannan, R. W., and Hudelson, K. S. 1998. Trichomoniasis in Cooper's Hawks from Arizona. J. Wildlife Diseases 34:590-593; doi.org/10.7589/00903558-34.3.590.

Bosakowski, T., Speiser, R., Smith, D. G., and Niles, L. J. 1993. Loss of Cooper's Hawk nesting habitat to suburban development: Inadequate protection for a state-endangered species. J. Raptor Res. 27:26-30.

Chamberlain, D. E., Cannon, A. R., Toms, M., Leech, D., Hatchwell, B., and Gaston, K. 2009. Avian productivity in urban landscapes: A review and meta-analysis. Ibis 151:1-18; doi.org/10.1111/j.1474-919X.2008.00899.x.

Chiang, S. N., Bloom, P. H., Bartuszevige, A. M., and Thomas, S. E. 2012. Home range and habitat use of Cooper's Hawks in urban and natural areas. Studies Avian Biol. 45:1-16.

Estes, W. A., and Mannan, R. W. 2003. Feeding behavior of Cooper's Hawks at urban and rural nests in southeastern Arizona. Condor 105:107-116; doi.org/10.1093/ condor/105.1.107.

Mannan, R. W., and Boal, C. W. 2000. Home range characteristics of male Cooper's Hawks in an urban environment. Wilson Bull. 112:21-27; doi.org/10.1676/00435643(2000)112[0021:HRCOMC]2.0.CO;2.

Mannan, R. W., Steidl, R. J., and Boal, C. W. 2008. Identifying habitat sinks: A case study of Cooper's Hawks in an urban environment. Urban Ecosystems 11:141-148; doi.org/10.1007/s11252-008-0056-9.

Mayfield, H. 1961. Nesting success calculated from exposure. Wilson Bull. 73:255261.

Millsap, B. A. 2018. Demography and metapopulation dynamics of an urban Cooper's Hawk subpopulation. Condor 120:63-80; doi.org/10.1650/condor-17-124.1.

R Core Team. 2017. R: A language and environment for statistical computing. $\mathrm{R}$ Foundation for Statistical Computing, Vienna, Austria; https://R-project.org/.

Reynolds, R. T. 1983. Management of western coniferous forest habitat for nesting accipiter hawks. U.S. Forest Service Tech. Rep. RM-102; doi.org/10.2737/ RM-GTR-102.

Reynolds, R. T. 1989. Status reports: Accipiters, in Proceedings of the Western Raptor Management Symposium and Workshop (B. G. Pendleton, C. E. Ruibal, D. L. Krahe, K. Steenhof, M. N. Kochert, and M. L. LeFranc, eds.), pp. 92-101. Natl. Wildlife Fed., Washington, DC.

Rosenfield, R. N., Bielefeldt, J., Anderson, R. K., and Papp, J. M. 1991. Status reports: Accipiters, in Proceedings of the Midwest Raptor Management Symposium and Workshop (B. G. Pendleton, D. L. Krahe, M. N. LeFranc, Jr., K. Titus, J. C. Bednarz, D. E. Andersen, and B. A. Millsap, eds.), pp. 42-49. Natl. Wildlife Fed., Washington, DC.

Rosenfield, R. N., Bielefeldt, J., Affeldt, J. L., and Bechmann, D. J. 1995. Nesting density, nest area reoccupancy, and monitoring implications for Cooper's Hawks in Wisconsin. J. Raptor Res. 29:1-4.

Rosenfield, R. N., Hardin, M. G., Taylor, J., Sobolik, L. E., and Frater, P. N. 2019a. Nesting density and dispersal movements between urban and rural habitats 


\section{NESTING BIOLOGY OF URBAN COOPER'S HAWKS}

of Cooper's Hawks (Accipiter cooperii) in Wisconsin: Are these source or sink habitats? Am. Midland Nat. 182:36-51; 10.1674/0003-0031-182.1.36.

Rosenfield, R. N., Madden, K. K., Bielefeldt, J., and Curtis, O. E. 2019b. Cooper's Hawk (Accipiter cooperii), version 3.0, in The Birds of North America (P. G. Rodewald, ed.). Cornell Lab Ornithol., Ithaca, NY; doi.org/10.2173/bna. coohaw.03.

Rullman, S., and Marzluff, J. M. 2014. Raptor presence along an urban-wildland gradient: Influences of prey abundance and land cover. J. Raptor Res. 48:257-272; doi.org/10.3356/JRR-13-32.1.

Steenhof, K.,M., Kochert., N., McIntyre, C. I., and Brown, J. L. 2017. Coming to terms about describing Golden Eagle reproduction. J. Raptor Res. 51:378-390; doi.org/10.3356/JRR-16-46.1.

Stout, W. E., and Rosenfield, R. N. 2010. Colonization, growth, and density of a pioneer Cooper's Hawk population in a large metropolitan environment. J. Raptor Res. 44:255-267; doi.org/10.3356/JRR-09-26.1.

Stout, W. E., Rosenfield, R. N., Holton, W. G., and Bielefeldt, J. 2007. Nesting biology of urban Cooper's Hawks in Milwaukee, Wisconsin. J. Wildlife Mgmt. 71:366-375; doi.org/10.2193/2005-664.

Accepted 20 May 2020 